\title{
La voz de una carne \\ desconocida y secreta \\ (La voz y el instante de la angustia)
}

\section{The voice of an unknown and secret flesh (The voice and the instant of angst)}

\section{Alejandro Beretta}

\section{RESUMEN:}

En este trabajo se indagan las relaciones entre la noción de voz, tal como es formulada por Jacques Lacan, es decir, caracterizándola como alteridad al decir y ubicándola como objeto $a$, y otros conceptos psicoanalíticos. Principalmente se destaca la conexión entre la voz y la angustia en la articulación del nombre y la función del padre. En el punto de angustia se precipita la tensión entre lalengua -lalangue- y la lengua. En ese punto se conjugan una proliferación de voces que resuenan en el cuerpo y la escritura del nombre propio que trata de morigerarlas. Entre la continuidad, como simultaneidad de voces anónimas e invasivas, y la discontinuidad correlativa a la represión. La angustia se sitúa en el límite donde se vislumbra un continuo que no avanza ni retrocede y que hace que distintas voces, distintos deseos se conecten entre sí y que parezcan ramificarse al infinito.

Palabras Clave:

Voz - angustia - instante - nombre función del padre
SUMMARY:

This paper tackles the relations among the notion of voice, as defined by Jacques Lacan, i.e., characterized as otherness from saying and placed as object $a$, and other psychoanalytic concepts. What is mainly highlighted is the connection between voice and angst in the articulation of the name and the function of the father. The tension between lalangue and language thickens in the point of angst. In this point a proliferation of voices resounding in the body merges with the writing of the proper name trying to restrain them. Between continuity, as a simultaneity of anonymous and invasive voices, and the discontinuity correlative to repression. Angst is located in the boundary where a continuum is discerned, neither moving forward nor backward, and making different voices, different desires connected to one another and looking as if they ramify ad infinitum.

WORD PAD:

Voice - angst - instant - name - function of the father 



\section{I-El LlAMAdo Al OTRO}

En los Seminarios 10 y 11 al comentar la articulación de la pulsión con el campo del Otro, Lacan acentúa la intervención de un movimiento de llamada que apunta a la respuesta del Otro. En la clase xv del $\mathrm{Se}$ minario 11 después de revisar los distintos objetos de cada pulsión plantea que:

¿Qué nos revela este sobrevuelo? ¿No parece que en esta vuelta que representa su red, la pulsión al invaginarse a través de la zona erógena está encargada de ir a buscar algo que, cada vez, responde en el Otro? No remitiré a la serie. Digamos que al nivel de la Schaulust es la mirada. Sólo lo indico para tratar más adelante de los efectos en el otro de este movimiento de llamada. (Lacan, I963 a, p.20I)

El llamado al Otro se conjuga, en dichos seminarios, con los mecanismos de alienación y separación, y también con esa pregunta fundamental que Lacan (I960) en el texto Subversión del sujeto ubica en la relación del sujeto con el Otro: Che vuoi? - ¿Qué quieres? - que viene de la boca del Otro. Esta pregunta alude al superyó y también alcanza una dimensión de interrogación con respecto al significante y al deseo. El llamado al Otro recibe como respuesta esas dos dimensiones que evoca el "Che vuoi?" (LACAN, I960).

El llamado al Otro, inexorablemente imbricado al tema de la enunciación, involucra dos instancias fundamentales: la voz y el tiempo.

En relación al circuito de la pulsión, ese movimiento de llamada fue leído por algunos analistas como "la cara invocante de toda pulsión” (Glasman, I993). Esta idea da una pista de la fuerte incidencia de la problemática de la voz en la articulación de la relación del sujeto y el Otro. En la clase xx del Seminario 10, Lacan plantea que la voz no resuena en ningún vacío espacial, resuena en el vacío del Otro, el vacio de su falta de garantías. "La voz responde a lo que se dice, pero no puede responder de ello. Dicho de otra manera, para que responda, debemos incorporar la voz como alteridad de lo que se dice" ( I962, p. 298). La respuesta del Otro involucra una voz muda como alteridad correlativa al decir. Una voz que concierne al lenguajey que a la vez es siempre exterior a él. Voz que Lacan caracteriza distinguiéndola de las sonoridades:

La verdad entra en el mundo con el significante, antes de cualquier control. Se experimenta, se trasmite mediante sus ecos en lo real. Ahora bien, es en este vacío en donde resuena la voz como distinta de las sonoridades, no modulada sino articulada. La voz en cuestión es la voz en tanto que imperativo, en tanto reclama obediencia o convicción. Se sitúa, no respecto a la música, sino respecto a la palabra. (Lacan, I962, p.298)

La voz como resto que se incorpora en la relación con el Otro, adquiere en la argumentación de Lacan el estatuto de objeto a. La respuesta del Otro involucra al sujeto en la incorporación de lo inasimilable, operación que Lacan distingue de la introyección kleiniana que presupone una positividad a introyectar. La voz como alteridad al decir solo se circunscribe, como respuesta del Otro, en el movimiento de espera y desaparición, y tal como señala Blanchot "nos hace mudos del habla que le debemos” (BLANChot, I990, p.30).

Ya en el campo de la lingüística se genera una paradoja con la voz como indica Dólar, "puede no haber una lingüística de la voz, y sin embargo la no-voz que representa a la voz no domesticada por la 
estructura no es externa a la lingüística" (Dolar, 2006, p.45).

La voz como objeto a que resuena en el vacío del Otro tiene una conexión decisiva con los afectos, en especial con la angustia. La voz es correlativa al corte que introduce la angustia. Corte que Lacan caracteriza en estos términos:

La angustia es ese corte - ese corte sin el cual la presencia del significante, su funcionamiento, su surco en lo real, es impensable-, es este corte que se abre y deja aparecer lo que ahora entenderán ustedes mejor, lo inesperado, la visita, la noticia, lo que expresa tan bien el termino presentimiento, que no debe entenderse simplemente como el presentimiento de algo, sino también como el pre-sentimiento, lo que está antes del nacimiento de un sentimiento. (LACAN, I962, p.87).

La voz pulsada como un eco por la repetición repercute en el cuerpo como afecto, como aquello que la memoria no alcanza a inscribir ni a olvidar. En este sentido se puede leer todo el trabajo de argumentación que realiza Lacan sobre el shofar, en el capítulo XVIII (I962, p.264) del Seminario 10. De un modo rapsódico va comentando un artículo de Theodor Reik sobre el uso religioso de este instrumento. Lacan va correlacionando el sonido del shofar en los ritos religiosos, con el acto y con la repetición, en estos términos:

La cuestión tiene mucha importancia, porque nos conduce al terreno en que se dibujó en su forma más fulgurante, en el espíritu de Freud, la función de la repetición. La función de la repetición, ¿es únicamente automática y esta exclusivamente asociada al retorno, al necesario carreteo de la batería significante? ¿O bien tiene otra dimensión? $\mathrm{Me}$ parece inevitable encontrar esta otra dimensión en nuestra experiencia, si es que esta tiene algún sentido. Esta dimensión nos da el sentido de la interrogación de la que es portador el lugar del Otro. Para decirlo todo, ¿acaso aquel en quien en este caso se trata de despertar el recuerdo, de hacer que se acuerde no es el propio Dios? (Lacan, I962, p. 27I)

El sonido del shofar, según Lacan, en la tradición judía conmemora el pacto con Dios —el diálogo con Moisés que nadie presenció-, su función se manifiesta "en esas fiestas anuales en tanto que ellas mismas se refieren a la repetición y la rememoración de esa alianza" (LACAN, I962, p.27I). El sonido del shofar evoca la voz inaudible de Dios, voz irremediablemente perdida.

Además y elípticamente, en su argumentación Lacan hace una referencia al afecto en relación con el shofar, en estos términos:

Quienes se hayan regalado o se regalen esta experiencia darán testimonio, creo, del carácter-digamos, para permanecer dentro de límites que no sean demasiado líricosprofundamente conmovedor, inquietante, de esos sonidos. Con independencia de la atmósfera de recogimiento, de fe, incluso de arrepentimiento, en la que se manifiestan y resuenan, surge una emoción nada habitual por las vías misteriosas del afecto propiamente auricular que no pueden dejar de conmover, en un grado verdaderamente insólito, a todos aquellos que se ponen al alcance de oírlos. (LACAN, I962, p.267)

La referencia a la voz, como objeto a que se separa a partir de la relación con el Otro, es correlativa a la aparición del afecto. Lacan comenta que algo sucede en el cuerpo, que surge una emoción por las vías misteriosas del afecto auricular. 
La repetición convoca la intervención de esa voz muda en el instante donde todavía no hay saber, voz que no está hecha para el recuerdo, ni para el olvido, pero que repercute en el cuerpo. En la fenomenología del análisis esto surge en algunas ocasiones como la inquietante y extraña imposibilidad de recordar la voz paterna o también como angustia ante el superyó en términos freudianos.

En relación con esa voz se articula la relación del superyó con la angustia. Para Lacan el superyó es un imperativo de goce, "el lugar de la angustia surge después que el deseo del Otro ha adquirido la forma de mandamiento" (LACAN, I963).

Lacan también acentúa que, tanto la culpabilidad como el sacrificio a los dioses, se enmarcan en el movimiento del llamado al Otro, apuntan a la intervención del objeto a en el campo del deseo del Otro, que la angustia señala.

Con respecto al sacrificio plantea que: "El sacrificio significa que en el objeto de nuestros deseos intentamos encontrar el testimonio de la presencia del deseo de ese Otro, que aquí llamo el Dios Oscuro" (LACAN, I963 a, p.278). El sacrificio intenta invocar y a la vez atemperar los rastros de la voz del "Dios oscuro", es decir, apaciguar la angustia. En cuanto a la culpabilidad sostiene que a partir de la instauración del superyó, la angustia se puede resolver como culpabilidad mediante la función del nombre del padre.

La culpa encubre y sostiene ese lugar de falta inicial en el deseo del Otro, la culpabilidad cubre a la angustia. Al respecto Lacan comenta que:

Que el deseo sea falta, diremos que es su fallo inicial, en el sentido de que hace falta. Cambien el sentido de esa falta dándole un contenido - ¿en la articulación de qué?, dejémoslo en suspenso-, y he aquí lo que explica el nacimiento de la culpa y su relación con la angustia. (LACAN, I962, p.299)

La voz como objeto a se ubica así entre el goce yla responsabilidad, en ese sentido Lacan hace referencia a la voz de Sócrates: "Piensen en Sócrates. La pureza inflexible de Sócrates y su atopía son correlativas. Interviniendo en todo momento ahí la voz demoníaca. ¿Dirán que la voz que guía a Sócrates no es el propio Sócrates?” (LACAN, I963 a, p.262).

La voz demoníaca de Sócrates es una voz interior, no fonemática, es esencialmente imperativa, pero sin un contenido preciso, es una voz muda por lo tanto en varios sentidos del término. Una voz ligada a la responsabilidad y a lo demoníaco.

La voz como alteridad a lo que se dice remite a esa voz muda anterior al dicho, pero que en el movimiento del decir se constituye como resto. Voz también ligada a la escritura y a la problemática del nombre propio. Por esto Lacan se pregunta: “¿Dirán que la voz que guía a Sócrates no es el propio Sócrates?” (LACAN, I963 a). Lo intraducible del nombre propio remite a aquello que se pierde como voz. La voz, como alteridad al decir surge como lo no nombrado de la escritura y como lo no escrito de la fonetizacion.

En el esfuerzo del significante para nombrar al ser viviente, el eco de esa voz inaudible se instala como una grieta mortal, ese es el terreno del nombre propio. El nombre propio, en tanto letra, se constituye como la marca del límite que la voz impone al significante. En este sentido el decir como acto inscribe algo, deja una marca que para constituirse en escritura requiere de una voz muda que la funde. La problemática de la escritura en la obra 
de Lacan se vincula al rasgo unario. Como advierte Ritvo:

La paradoja de la escritura es que por no tener voz, en el sentido de phoné, fonación, fonetización, adquiere finalmente voz, porque tiene que inventarla. La escritura inventa la voz que no tiene. En una escritura surgida así, en los límites de la privación, lo que hay que interrogar es lo que permanece mudo en la fonación, precisamente porque esa mudez es ya voz. (...) La escritura inventa la voz que no tiene. Esta función es tan desbordante que le otorga a la escritura la posibilidad de plantear problemas de suplementación respecto a la lengua de la que parte. (Ritvo, I994, p.88)

Si la problemática del nombre propio se enlaza con la pregunta ¿Qué soy yo?, Lacan en Subversión del sujeto ensaya una respuesta:

¿Qué soy yo (je)?

Soy en el lugar desde donde se vocifera «que el universo es un defecto en la pureza del No-Ser ».

Y esto no sin razón, pues de conservarse, ese lugar hace languidecer al ser mismo. Se llama el Goce, y es aquello cuya falta haría vano el universo. ¿Está pues a mi cargo? -Sin duda que sí. Ese goce cuya falta hace inconsistente al Otro, ¿es pues el mío? La experiencia prueba que ordinariamente me está prohibido, y esto no únicamente, como lo creerían los imbéciles, por un mal arreglo de la sociedad, sino, diría yo, por la culpa del Otro si existiese: como el Otro no existe, no me queda más remedio que tomar la culpa sobre Yo $(J e)$, es decir creer en aquello a lo que la experiencia nos arrastra a todos, y a Freud el primero: al pecado original. (LACAN, I960, p.800)

Lo invocante de la pulsión se despliega "en el lugar donde se vocifera que el uni- verso es un defecto en la pureza del NoSer", lugar inherente a la responsabilidad $\mathrm{y}$ al goce que el lenguaje propone al decir. En relación con esto, Dolar, indagando en la historia de la metafísica, contrapone dos tendencias en las concepciones de la voz: una como portadora del logos, del sentido y de la Ley, y otra tendencia que conecta a la voz con el goce, la femineidad y la otredad. Entonces, plantea que existiría una "lucha" entre voces, una lucha de "la voz contra la voz" (DolAR, 2006, p.7I). Al respecto se pregunta si:

¿Difiere sin embargo por completo esa voz inaudible, pertinente al logos, de la voz maldita que acarrea goce ilimitado y decadencia? ¿Es el goce que la ley persigue como su alteridad radical otra cosa que el aspecto de goce pertinente a la ley misma? $¿$ Es la voz del Padre una especie por completo diferente de la voz femenina? (DOLAR, 2006, p.7I)

Al respecto dirá que "ambas son la misma, es que no hay dos voces, sino solamente el objeto voz que se escinde y barra al Otro en una misma inalienable extimidad" (Dolar, 2006, p.7I). Este desdoblamiento de la voz da cuenta de las dos caras del superyó freudiano, una conectada con los ideales de la cultura tras la cual se encuentra la otra cara demoníaca.

En los impases del deseo, la voz se manifiesta como voz infernal que toma cuerpo y toma al cuerpo en el momento de la angustia, cuando el objeto a está adelante y no funciona como causa. En ese tiempo sin sujeto, donde hay sujeto por venir y objeto por faltar, el objeto es la Cosa que antecede al sujeto

La voz como voz exterior al lenguaje está en la raíz y en la consecuencia del decir, marcando con su impronta las crea- 
ciones que instituye el orden simbólico. La creación ex-nihilo es un tema recurrente en Lacan, por ejemplo en relación a la voz argumenta que:

La más simple inmixión de la voz en lo que se llama lingüísticamente su función fática —se cree que ésta se sitúa en el nivel de la simple toma de contacto, cuando se trata ciertamente de otra cosa- resuena en un vacío que es el vacío del Otro en cuanto tal, el ex nihilo propiamente dicho. La voz responde a lo que se dice, pero no puede responder de ello. (LACAN, I962, p.293)

La nada como antecedente es la que el decir en acto inventa como precedente. Como señala Borges, el creador literario inventa sus precursores (BORGES, I974). La creación del poeta deja escuchar los ecos de otras voces infernales que balbucean en su propia voz.

Si Lacan correlaciona al Goce con el no-ser, esa es la nada de la que parte la creación, ese es el material que transforma e inventa cada vez el poeta. El creador reescribe en nombre propio el conflicto entre las pulsiones de vida y la pulsión de muerte.

En este sentido, el texto El malestar en la cultura es la reescritura de Más allá del principio del placer. Si Freud (I939) pretendía que su texto sobre Moisés fuera leído como una novela histórica, es porque quizás presentía los ecos de otras voces en su propia voz.

Freud, en el Creador literario y el fantaseo, utiliza la metáfora del deseo como un collar que en la fantasía engarza las tres dimensiones temporales. Escribe que: "pasado, presente y futuro son como las cuentas de un collar engarzado por el deseo" (Freud, I907, p.I30). En cuanto al creador, se pregunta de dónde obtiene sus materiales y cuál es la clave del trabajo, de su arte. Con respecto a los materiales plantea que son los mismos con los que se enfrenta la represión: las mociones pulsionales. Freud, creador y arqueólogo a la vez, en el texto sobre Moisés (I939), juega, escribe, con las ruinas y los distintos tiempos de la historia, en el medio del clamor y el rumor de esas voces que sin encenderse ni apagarse constituyen la tradición del pueblo judío.

La voz, en el instante de la angustia, surge en el punto límite en donde la pulsión, todavía no tomada por el tiempo del síntoma, puede sofocarse por las vías de la sublimación. La sublimación es el tiempo del objeto pulsional en tensión con el ideal, pero procesado por una vía distinta a la del síntoma. La sublimación le da un tiempo al coro de esas voces infernales que configuran la obra de arte.

El instante de la angustia es el tiempo del llamado al Otro o también el llamado del tiempo, el momento en donde el tiempo adviene como donación.

Derrida plantea "que la diferencia entre un don y cualquier otra operación de intercambio puro y simple es que el don da el tiempo (...) pero ese don del tiempo es asimismo una petición de tiempo" (DERRIDA, I995, p. 47).

Acerca del tiempo como donación Derrida plantea que:

Un don no podría ser posible, no puede haber don sino en el instante en que una fractura haya tenido lugar en el círculo: en el instante en que toda circulación haya sido interrumpida y a condición de ese instante. $\mathrm{Y}$, además, dicho instante de fractura (del círculo temporal) ya no debería pertenecer al tiempo. Por eso hemos dicho "a condición de ese instante". Esta condición concierne al tiempo pero no le pertenece, no depende de él, mas no por ello es ésta más lógica que 
cronológica. No habría don sino en el instante en el que el instante paradójico (en el sentido en que Kierkegaard dice que el instante paradójico de la decisión es la locura) desgarra el tiempo. En este sentido, jamás habría el tiempo de un don. En cualquier caso, el tiempo, el "presente" del don ya no se puede pensar como un ahora, a saber, como un presente encadenado a la síntesis temporal. (DERRIDA, I995, p. I9)

El llamado al Otro, como decir desdoblado por la voz, supone que a partir del decir, con el circuito pulsional y el objeto a se empieza a poner en juego el tiempo. Tiempo que se articulará en la retroactividad del síntoma con un objeto que elude el presente. El instante de la angustia, elidido en el fantasma, coincide con el llamado al Otro, es el punto donde la voz resuena en el cuerpo.

En el texto Kant con Sade, Lacan partiendo de su concepción del objeto a, cuestiona la concepción del tiempo como forma pura. Después de plantear que el objeto a como agente del tormento en el fantasma sádico está ahí "develado como Ser-allí, Dasein” (LACAN, I963 c, p.75I), sostiene que el objeto se devela, conservando su opacidad. Al respecto plantea que:

No sin conservar la opacidad de lo trascendente. Pues ese objeto está extrañamente separado del sujeto. Observemos que el heraldo de la máxima no necesita ser aquí más que punto de emisión. Puede ser una voz en la radio, que recuerda el derecho promovido por el suplemento de esfuerzo que ante el llamado de Sade los franceses hubieran aceptado, y la máxima convertida para su República regenerada en Ley orgánica. Tales fenómenos de la voz, concretamente los de la psicosis, tienen efectivamente este aspecto del objeto. Y el psicoanálisis no es- taba lejos en su aurora de referir a ellos la voz de la conciencia.

Se ve lo que motiva a Kant a considerar ese objeto como hurtado a toda determinación de la estética trascendental, aun cuando no deja de aparecer en algún chichón del velo fenomenal, ya que no carece de lugar, $\mathrm{ni}$ de tiempo en la intuición, ni de modo que se sitúa en lo irreal, ni de efecto en la realidad: no es sólo que la fenomenología de Kant falle aquí, es que la voz incluso loca impone la idea del sujeto, y que no es preciso que el objeto de la ley no sugiera una malignidad del Dios real. (LACAN, 963 c, p.75I)

Lacan plantea que el tiempo adviene a partir del objeto $a$, a partir del impacto de esa voz exterior al lenguaje que se separa del sujeto, y que además es por el llamado al Otro, en el decir, que se temporaliza el instante. Instante que elude el presente, como lo señala Deleuze, el instante sin pasar por el presente se dirige a la vez al pasado y al futuro (Deleuze, 2005). Por este motivo no se puede concebir al tiempo como forma pura.

La voz infernal entre el goce y la responsabilidad se conecta con el tiempo en el instante de la angustia para modelar el lugar de la pulsión. Es el tiempo que incide en el cuerpo como afecto. La angustia se caracteriza como tiempo de espera que es a su vez espera del tiempo, una petición de tiempo, de temporización en la cual el objeto escapara al presente. Si la angustia no es sin objeto, también el tiempo no es sin objeto. Los afectos son los rastros en el cuerpo del encuentro entre el objeto y el tiempo.

\section{2- El instante De la Angustia}

El instante de la angustia conjuga el encuentro del tiempo y la voz. La voz como 
alteridad al decir se desdobla entre la proliferación de voces anónimas y la escritura del nombre propio. Esas voces que no se inscriben en la partitura del deseo resuenan en el cuerpo traducidas como angustia. Más allá del recuerdo y del olvido, el eco de esas voces es tensión por venir que irrumpe con el decir. Tensión que, a su vez, se redobla entre el autoerotismo y el objeto, entre el yo y las pulsiones parciales.

Lacan sitúa el instante de la angustia como tiempo previo del deseo, tiempo del sujeto en vías de constitución. También Freud ubica a la angustia como premisa del síntoma. Para ambos, la angustia es fundamentalmente expectativa. En Inhibición, sintoma y angustia, comentando el caso del pequeño Hans, Freud señala a propósito de la angustia: "se trata de una determinada expectativa angustiada: el caballo lo morderá" (Freud, I 926, p.97).

En el instante del llamado al Otro, surge esa voz muda que al conjugarse con el tiempo es latencia sin consistencia que se sustrae a las determinaciones. Es el punto donde la pulsión parcial es tendencia sin finalidad que se hurta a las representaciones y que será necesario ligar desde el deseo para que no aparezca como angustia. La angustia señala aquello que no tiene lugar en la memoria pero que insiste tensado por el tiempo en la repetición, como insistencia de lo indeterminado en el juego de las determinaciones.

Según Lacan el objeto $a$ está adelante en la angustia y detrás en el circuito del deseo oficiando como causa (LACAN, I962). Entre el delante y el detrás hay salto sin mediación ni transición, hay repetición que hilvana un acto que constituye al sujeto y que introduce dos órdenes heterogéneos.

Con la repetición se produce un corte entre un antes y un después que no constituyen una continuidad, es decir, no están en el mismo tiempo. La repetición repite lo que antes no estaba ahí: la división del sujeto en acto, que se concreta como la huella de su desaparición en la cadena significante, y también actualiza la confrontación con la tensión del objeto a, es decir, la presión sincopada de la Cosa en el desfallecimiento del significante.

La angustia surge cuando está suspendido el orden del deseo, entonces el objeto a se articula como amenaza por venir, como expectativa. La angustia es la inminencia del objeto a en el momento previo a que éste oficie como causa de deseo. Como señala Kuri:

[...] sin la temporalidad sería imposible articular con rigor el vínculo de la angustia con la castración. En sentido estricto no es la castración lo que angustia (no es el complejo de castración que involucra la falta en el Otro), es la castración por venir. [...] La temporalidad requerida para situar a la angustia de castración hace indispensable no confundir la castración propia del acto de instauración del deseo, de la castración como presentimiento elaborada en la angustia. (KuRI, 995, p.I87)

El instante de la angustia se da con la repetición que permite la inscripción psíquica, o mejor dicho, con la reinscripción tal como plantea Freud en la Carta 52 a Fliess, es decir, de tanto en tanto se hace necesario, en el límite de dos épocas, una nueva traducción del material psíquico, repetición que involucra la castración como porvenir, y no como algo logrado. La repetición, en términos kierkegaardianos, genera su inmanencia posterior, en ese sentido la castración se involucra con la falta en el Otro. 
En el trabajo de apertura y cierre del inconsciente, la repetición conjuga el antes propio de la angustia con el velo de un después ya en el orden del deseo. Lo no logrado de la represión interviene como expectativa muda, como monto de afecto que excede a las determinaciones inconscientes, como latencia eterna de la voz que la represión no logra domeñar.

La pulsación temporal, entre la apertura y el cierre del inconsciente, confronta lo atemporal - la eternidad en espera o lo inmemorial- con el tiempo. En la repetición el inconsciente se conecta con lo real, con el objeto a, de manera fallida desde el deseo y el ámbito de la representación y como manifestación corporal en la angustia. En ambos planos se evidencia una dinámica temporal en la intervención del objeto a. En el deseo, el objeto a se hurta al presente, y en la angustia, la presión del tiempo es expectativa sin finalidad, tiempo fuera de sus goznes, proliferación de voces resonando en el vacío del Otro.

Cuando el significante engendra el mundo, el mundo del ser que habla es una red de huellas. El paso de un ciclo a otro en ese mundo se da con el decir y el corte que produce la angustia, sin ese corte, para Lacan, el significante no trazaría su surco en lo real (LACAN, I963 a). El decir cuenta con el tiempo para realizar sus inscripciones. La voz entre un ciclo y otro resuena como anticipación de lo real en el cuerpo, como lo que el significante no logra inscribir y se traduce como angustia. Entre un ciclo y otro, en el corte de la circularidad del tiempo, con el instante se introduce el tiempo, el desorden del tiempo. El impacto del objeto a no se da sobre un marco temporal previo, el tiempo impacta con el objeto en la angustia. El objeto es una petición de tiempo. El impacto del tiempo marca que el sujeto está precedido por una certeza siniestra que concierne a lo real. Como señala Lacan a propósito de la duda del obsesivo:

La angustia no es la duda, es la causa de la duda (...) La duda, los esfuerzos que invierte, todo ello no es sino para combatir la angustia, y precisamente mediante engaños. Es que se trata de evitar lo que en la angustia es certeza horrible. (LACAN, I962, p.88)

El antes de la angustia o la precedencia del a se vislumbra como procedencia horrible desde el síntoma. Lacan acentúa "que el significante es la huella del sujeto en el curso del mundo" (LACAN, I962, p.89) y también que la angustia escapa al juego de engaños o de ficciones que propone el significante. El curso del mundo puede leerse como metáfora temporal, equiparable a lo que Freud denominaba como la corriente de la vida (Strom des Lebens). En el curso del mundo, con la repetición como encuentro fallido con lo real, emerge el instante, siempre antes y después de sí mismo, el tiempo a destiempo de la corriente de la vida, en el límite de la angustia.

En el orden del deseo lo real insiste como causa fuera del curso del mundo. Real que en el despertar en el sueño de los cirios conmueve al padre, en el "punto más cruel del objeto" (LACAN, I963 a, p.69). La angustia en el despertar es certeza horrible del encuentro entre "la voz de aquel que siempre duerme con aquel que se ha dormido para no despertar" (LACAN, I963 a, p.69).

El doble sentido del despertar, que por un lado conecta al sujeto con lo real, con esa voz que irrumpe y trastoca la corriente de la vida, y por otro lo vuelve a situar en 
la realidad, en el curso del mundo, es ejemplar para pensar el lugar de término medio de la angustia entre el deseo y lo real. El salto, sin transición, entre un orden y otro, interrumpe la corriente de la vida para volver a retomarla.

El tiempo de la angustia es el instante del salto, el punto de la irrupción de un tiempo fuera de sus goznes, puro devenir sin finalidad ni origen, que compele a la creación o al espanto. Instante que, como señala Deleuze, corresponde a un "tiempo que se ha liberado del Yo, del Mundo y de Dios" (Deleuze, I983). Tiempo que se ha liberado de la representación, pero no del decir.

\section{3- LA VOZ Y EL NOMBRE}

En el punto de angustia se precipita la tensión entre lalengua -lalangue- y la lengua. Entre esa proliferación de voces que resuenan en el cuerpo y la escritura del nombre propio que trata de morigerarlas. Entre la continuidad, como simultaneidad de voces anónimas e invasivas, y la discontinuidad correlativa a la represión. La angustia se sitúa en el límite donde se vislumbra un continuo que no avanza ni retrocede y que hace que distintas voces, distintos deseos se conecten entre sí y que parezcan ramificarse al infinito. A propósito del neologismo lalangue una de las ideas que Lacan sugiere sobre este término es la siguiente:

Una lengua entre otras no es sino la integral de los equívocos que su historia ha dejado persistir. Es la veta en la que lo real (el único que es para el discurso analítico motivo de suceso: lo real de que no hay relación sexual) ha dejado su sedimento en el curso de los siglos. (LACAN, I97I, p.I I)
La manera en la que deja sus sedimentos es a través del decir, de la repetición que borra sus huellas para conservarlas en el límite de lo siniestro. La referencia al cálculo infinitesimal - la integral- en la especificación del término lalangue se conecta con la idea de infinito, con la amenaza de la proliferación asfixiante y terrorífica de los equívocos y sentidos dispares que se sedimentan en el curso de los siglos. Referencia urdida en la repetición del llamado al Otro con el curso del tiempo.

La amenaza de la ramificación infinita de todos esos dichos y equívocos dispersándose en un tiempo fuera de sus goznes debe ser conjurada para que la lengua sea habitada. Los ecos de distintas voces resuenan en el decir, mortificando al cuerpo con el peso de sus pasiones.

El instante de la angustia concierne entonces a la presión de lalangue sobre el decir.

Cuando Lacan sobre el final del Seminario 10, La angustia, comenta los distintos niveles del objeto a y lo pulsional, al tratar el nivel invocante se interesa en el término introyección conectándolo con la función auditiva y también con el funcionamiento del nombre del padre (LACAN, I962).

Con respecto a la función auditiva se puede plantear que el oído, al carecer de escansión, es el sentido más ineficaz para filtrar el efecto intrusivo de la palabra del Otro. En el nivel auditivo la insistencia de la voz, como alteridad del decir, es presión intolerable del tiempo que puede ser alivianada por la función del nombre.

En relación con la función paterna Lacan se pregunta si hay algo más en el mito freudiano del padre que la normalización del deseo en las vías de la ley. A lo que responde: 
¿Eso es todo? La propia necesidad de mantener el mito junto a lo que nos indica y nos hace perceptible la experiencia, incluso en los hechos que tantas veces sopesamos de la carencia de la función del padre, ¿acaso no atrae nuestra atención hacia algo distinto? - hacia lo siguiente, que en la manifestación de su deseo, el padre por su parte sabe a qué a se refiere dicho deseo. (LACAN, I962, p.364)

Lacan, como es remarcado por sus comentadores y tal como lo menciona en esta clase, comienza a teorizar sobre los nombres del padre en plural en vez de en singular, pero conservando para esta función el estatuto de mito, acentuando que con respecto a lo real todo abordaje es mítico. El mito del saber sobre el deseo es el mito correlativo a reintegrar el deseo a su causa. Es decir, de ubicar el a en el lugar de la causa. Lacan sostiene que:

Contrariamente a lo que enuncia el mito religioso, el padre no es causa sui, sino sujeto que ha ido lo suficientemente lejos en la realización de su deseo como para reintegrarlo en su causa, cualquiera que ésta sea, a lo que hay de irreductible en la función del a. Esto es lo que nos permite articular, en el principio mismo de nuestra investigación, sin eludirlo en forma alguna, que no hay sujeto alguno que no deba situarse como objeto, un objeto finito del que penden deseos finitos, los cuales sólo adquieren el aspecto de infinitizarse en la medida en que, al evadirse los unos de los otros cada vez más lejos de su centro, alejan al sujeto cada vez más de cualquier realización auténtica. (LACAN, I962, p.364)

En esta argumentación, Lacan insiste en que el sujeto debe situarse como objeto en el campo del Otro. El objeto $a$, comen- ta Lacan, en tanto real y como tal inalcanzable por el deseo, constituye "nuestra existencia más radical” (LACAN, I962, p.365). Situar el a en el campo del Otro es una fórmula compleja. ¿Cómo situar en el campo de los nombres algo que no puede ser nombrado? Lacan hace referencia a que "no sólo es que deba ser en él situado, sino que es situado en él por cada uno de nosotros y por todos" (LACAN, I962, p.365). La expresión cada uno de nosotros y todos pone énfasis en que se trata de un acto, más que de una operación abstracta. Situar el a en el campo del Otro es una operación singular y no generalizable, que excede al saber. Rápidamente Lacan la conecta con la posibilidad del despliegue de la transferencia, es decir del trabajo de la sustitución.

En ese marco, situar el objeto implica la confrontación con la angustia. Para Lacan, no "hay superación de la angustia sino cuando el Otro se ha nombrado" (LACAN, I962, p.365). Nombrar al Otro en un sentido es indicar a quién se dirige el sujeto, pero además es fundamentalmente un acto, que engendra el nombre propio.

La función del nombre se articula fundamentalmente en relación con el objeto a. Pronunciar un nombre, para Lacan, produce "la huella de algo que va de la existencia del a a su paso a la historia" (LACAN, I962, p.365). Esta fórmula permite pensar el salto entre esas voces que tienden a infinitizarse en el límite de la angustia y el síntoma que postula esa palabra, que es un dicho siempre por decir en un insistente futuro anterior. Palabra que irradia su tensión en la órbita del saber.

Hay así un salto entre la existencia más radical "en el lugar desde donde se vocifera que el universo es un defecto en la pu- 
reza del No-Ser" (LACAN, I960, p.800) y el paso a la historia donde el a surge como causa que hace languidecer al ser.

El $a$ en su encuentro con el tiempo pasa de la existencia a la historia. En la re-escritura del nombre propio, los nombres del padre ejercen la función de ubicar al a en el lugar de la causa, donde el objeto elude el presente. En cambio, en la angustia el objeto es voz sin nombre, presionada por un tiempo sin historia.

Es interesante que Lacan destaque en la función del padre la idea de que "el sujeto deba situarse como objeto finito del que penden deseos finitos, los cuales sólo adquieren el aspecto de infinitizarse en la medida en que alejan al sujeto cada vez más de cualquier realización auténtica" (LACAN, I962). Esta idea introduce la problemática de la decisión en el término acto. La angustia en tanto constricción, en tanto objeto a como petición de tiempo, precipita una decisión, un salto sin justificación ni saber previo. Ya en el Crátilo, Platón presenta la problemática más general de la arbitrariedad o la motivación del nombre relacionada con la idea de una decisión injustificada. Como señala Ritvo:

La noción a mi juicio central de "acto analítico" es inconcebible sin el privilegio que posee la palabra insustituible "decisión”. La dimensión del acto excede a la decisión, pero sin esta última el acto es una parodia de acto y acaba por rechazar la lección de la angustia, que es inminencia -tiempo de inminencia- de algo que, a la vez, puede salvarme y puede también perderme; algo que reclama una decisión e instala el suspenso del recurso del sujeto para sostenerse: “¿Podré?”. Ése es el grito vertiginoso. (Ritvo, 20Io, p.3)
También en la fórmula sobre el nombre como huella de algo que va de la existencia del a a su paso a la historia hay que remarcar el término huella. La huella se constituye en el pasaje a la historia. En el instante de la irrupción del tiempo a partir del decir y la voz como su alteridad, algo adviene como huella borrada. La huella porta al tiempo y a la voz. El nombre propio se constituye en el parloteo infernal de esas voces impropias que el nombre del padre intenta encauzar. La neurosis no es tanto una defensa contra la angustia, sino más "bien contra aquello cuya señal es la angustia” (LACAN, I962, p.I 52), es decir, contra esas voces que el acto de nombrar no deja de convocar. Voces que vienen con el tiempo y que el terreno del síntoma y su ilusión de la primera palabra, tan impronunciable como la última, no alcanza a exorcizar.

La historia empieza con la angustia, pero si el acto y la decisión que acarrea no ocurren, el sujeto no adviene, queda coagulado en la angustia.

En este sentido se puede seguir la perspicaz distinción clínica que realiza Le Poulichet entre un tiempo que pasa y otro que no pasa, aclarando que, más que un tiempo que no pasa, es la no ejecución del acto, o la no realización de la creación, lo que imposibilita historizar esa nada atroz que señala la angustia (Le Poulichet, I996). El tiempo no obra por sí solo, se conjuga con el decir y con la voz para constituir la historia. El tiempo es pulsación que irrumpe con el decir, y a su vez, con el decir, el sujeto hace su paso por la historia y la historia pasa por lo real. Por ejemplo, en el duelo, el trabajo minucioso de los representantes y el tiempo hacen que el sujeto se encamine hacia la elaboración. 
El tiempo de la angustia es tiempo de la existencia del a en su punto más espantoso, punto que genera esa horrible certeza que empuja hacia el acto. En el Seminario 11 , Los cuatro conceptos fundamentales del psicoanálisis, Lacan acentúa que la existencia de lo real es lo que permite que el psicoanálisis no sea un idealismo, es decir, aquello que Freud llamaba una ilusión (LACAN, I963 a). La existencia de lo real en la alternancia entre el síntoma y la angustia se inmiscuye en la historia como causa que elude el presente o como certeza siniestra y carente de saber en la angustia. Los deseos inconscientes, planteaba Freud, son indestructibles, la historia que cada sujeto construye le da tiempo a esos deseos, a esas ficciones que trazan sus surcos en lo real, siempre a destiempo de la corriente de la vida.

La voz, o las voces como alteridad al decir, entre el goce y la muerte, se apoderan de su tiempo, se temporalizan con la inscripción de la historia. Toda historia escrita en transferencia cuenta con la sexualidad y la muerte. Cuenta con la herencia errante de las voces que toman su tiempo, en el mejor de los casos para acallarse, pero nunca en un presente simple.

La escritura de la historia pone en juego la verdad como desamparo y no como desocultamiento. La verdad se asienta en la certeza del encuentro de lo real. En esta dirección es pertinente la traducción que propone Blanchot del término aletheia. Según Blanchot, dicho término puede ser traducido como desamparo, y en esta perspectiva aclara que su sentido leído por Platón —en el Crátilo- conduce etimológicamente a la significación de carrera errante, o desvario de los dioses. (BLANСНот, I983, p.84). En esta dirección Blanchot comenta que:
Por eso el cuidado de no insistir en la frase muy conocida: el lenguaje, morada del ser. Incluso en Platón el mito de la cueva es también el mito del amparo: arrancarse de lo que ampara, obviarlo, desampararse, tal es una de las peripecias mayores, no sólo del conocimiento, sino más bien condición de una "mudanza de todo el ser", como lo dice todavía Platón - vuelco que nos pone ante la exigencia de la vuelta (el tournant, kebre). Que comprometa al pensamiento hasta ese extremo tal o cual manera de traducir, es un hecho del que uno puede extrañarse, quejarse o concluir que la filosofía sólo es asunto de palabras. Nada que decir contra eso, sino que siempre es menester preguntarse, como lo sugería Paulhan, por qué una palabra es siempre más que una palabra. (Blanchot, I983, p.84).

Blanchot cuestiona la idea del lenguaje como morada del ser para acentuar la dimensión de inhospitalidad de las palabras, en consonancia con este planteo se ubica la noción de lalengua de Lacan. El decir arranca al sujeto del amparo de la reproducción del sentido, para llevarlo al momento decisivo - tournant, kebre-, donde una palabra es siempre más que una palabra, donde la menor palabra es todo el lenguaje o una pluralidad de lenguajes, de voces y de tiempos.

La traducción de aletheia como desamparo, como errancia o desvarío de los dioses no sólo cuestiona las concepciones de la verdad como desvelamiento y la del origen pleno del sentido, también introduce la idea de que el lenguaje tiene "una naturaleza de índole histórica” (Blanchot, I983, p.85).

Entre el objeto que el sujeto es para el Otro y el nombre propio, el lenguaje introduce el tiempo y la pluralidad de voces, 
como desvarío de los dioses, errancia sin finalidad ni agente. El tiempo de la angustia está impregnado por la inminencia intrusiva de lo real. En cambio, en el orden del deseo, lo real pasa por la historia esquivando el presente a través del síntoma y del fantasma.

En el seminario sobre Los Nombres del Padre, Lacan, a propósito de la voz como objeto a, plantea que Freud introduce el mito del padre ante lo inevitable de la pregunta ¿de quién el sujeto toma la voz? Al respeto sostiene que:

De este acceso originalmente fenomenológico, en relación con la voz del Otro, del pequeño a como caído del Otro, podemos agotar su función estructural llevando la interrogación sobre lo que es el Otro como sujeto. Por la voz, este objeto caído del órgano de la palabra, el Otro es el lugar donde todo aquello habla. Ya no podemos escapar a la pregunta: ¿quién?, más allá de aquel que habla en el lugar del Otro, y que es el sujeto, ¿quién es que está más allá, y de quien el sujeto, cada vez que habla, toma la voz?

Está claro que si Freud coloca el mito del padre en el centro de su doctrina es por lo inevitable de esta pregunta. (LACAN, I963 b, p.8)

Ante la pregunta ¿quién es que está más allá, y de quién el sujeto, cada vez que habla, toma la voz? Lacan introduce al nivel del padre la función del nombre. El nombre es esa marca, ya abierta a la lectura, y por eso es que se leerá de la misma forma en todas las lenguas, es decir como una forma siempre por venir, "algo está allí impreso, quizás un sujeto que va a hablar" (LACAN, I963 b, p.8). Lacan sitúa un tiempo de existencia radical del a, tal vez de la esencia ausente del cuerpo, coincidiendo con esas marcas, con algo que está allí im- preso, sujeto que está por hablar. En el significante existe esta dimensión que espera la lectura y es en este nivel donde se sitúa el nombre, como marca de lo no dicho en tanto límite del decir.

El nombre es el lugar donde se articula la función paterna, que conjuga la voz inaudible del goce, que convoca y compele a la lectura para darle tiempo y desdoblarla entre lo que aún no es y lo que ya no será. En esta dirección Lacan plantea que:

Dado este padre, quizá podamos ir más allá del mito tomando como referencia lo que implica el mito en este registro que nos hace progresar sobre estos tres términos: el goce, el deseo y el objeto. En efecto a continuación veremos con respecto al padre, ese padre para el cual Freud encuentra este singular equilibrio, esta suerte de conformidad de la ley y del deseo verdaderamente conjugados, necesitados el uno por el otro en el incesto, sobre la suposición del goce puro del padre como goce primordial. (LACAN, I963 b, p. IO)

La función nominal, al introducir la dimensión de la espera, hace converger en disyunción un goce primordial, como herencia por venir, y la posibilidad de instituir a las marcas del oráculo paterno, como marcas abiertas a la lectura.

La dimensión de la espera coincide con el tiempo de la angustia. En el paso de la existencia más radical del a hacia la historia, la espera es expectativa angustiada previa a la vacilación estructural del significante. Pasaje que se repite en la alternancia del síntoma y la angustia.

El objeto de la angustia se constituye en el rumor de esas voces en espera que, sin saber y sin nombre, determinadas por su indeterminación, reclaman su tiempo. El objeto de la angustia pone en juego eso 
que escapa al juego de la presencia y las determinaciones. Es eternidad en espera que, a diferencia de la eternidad platónica, es gestada por la discontinuidad del tiempo y sólo emerge en la dispersión evasiva de su retorno. El objeto a pasa de su existencia más radical a la historia transitando previamente el tiempo de la angustia, como vacío en espera del vocablo.

El nombre del padre, como tal impronunciable, sólo adquiere existencia en tensión con la dispersión que introduce la lectura. Si el nombre es siempre nombre de otro nombre, el nombre del padre se sostiene en la suposición de padre del nombre, creador del nombre primero de las cosas, como sostiene Lacan en el Seminario 23, El sinthoma.

El nombre propio es ficción de lo propio, que se articula en relación con una verdad que se disemina en el desvarío de las distintas voces que resuenan en el vacío del Otro; voces que vienen con el tiempo y se presentan en la novela familiar, como posteridad anterior, y luego como marcas a ser leídas en la transferencia. El trabajo analítico y la angustia, cada uno a su modo y de manera antagónica, deslindan la dimensión de lo que ya no es de otra que aún no es —eternidad en esperapero que aún puede ser.

En el comienzo, sin origen, el objeto y el tiempo circunscriben una zona que no tiene lugar en el concepto y que la angustia señala en el cuerpo. La anfibología del término voz caracteriza la dimensión temporal de espera y desaparición que estructura la angustia. La angustia es el cuerpo poblado de voces silenciosas y en espera, que no han comenzado y que no terminan. Voces que, como señala Blanchot "al no poder ubicarse en la historia son a la vez nuevas y antiguas, ante las cuales el sujeto deberá responder, como si fuesen lo imposible, lo que desde siempre ha desparecido entre las ruinas del objeto" (BLANChot, I990). Estas ruinas constituyen una herencia fragmentaria, que se dispersa sin unificación ni finalidad, presionando en el decir

Esas voces son las que evoca Barthes en El grado cero de la escritura cuando se refiere a la conformación del estilo, caracterizándolo como la voz decorativa de una carne desconocida y secreta, y plantea que:

La lengua está más acá de la Literatura. El estilo casi más allá: imágenes, elocución, léxico, nacen del cuerpo y del pasado del escritor (...) Así, bajo el nombre de estilo, se forma un lenguaje autárquico que se hunde en la mitología personal y secreta del autor, en esa hipofísica de la palabra donde se forma la primera pareja de las palabras y las cosas, (...) Sus referencias se hallan en el nivel de una biología o de un pasado, no de una Historia: es la "cosa" del escritor, su esplendor y su prisión, su soledad. (...) Es la voz decorativa de una carne desconocida y secreta; funciona al modo de una Necesidad, como si, en esa suerte de empuje floral, el estilo sólo fuera el término de una metamorfosis ciega y obstinada, salida de un infra lenguaje que se elabora en el límite de la carne y del mundo. (BARTHes, I973, pp.r 8-I9) 


\section{REFERENCIAS BIBLIOGRÁFICAS}

BAAs, B. (20I2). Lacan, la voz, el tiempo. Buenos Aires, Argentina, Letra Viva.

BARThes, R. (I987). "De la obra al texto" en El susurro del lenguaje. Buenos aires, Argentina, Editorial Paidós.

(2006). El grado cero de la escritura. (1973) Buenos Aires, Argentina, Siglo XXI Editores.

Blanchot, M. (1973). Nietzsche y la escritura fragmentaria. Buenos Aires, Argentina, Editorial Caldén.

(1990). La escritura del desas-

tre. México DF, México, Monte Ávila.

(I992). El espacio literario.

Barcelona, España, Editorial Paidós.

Deleuze, G. (1983). Clase de Filosofía: concepto / afecto / percepto, Pensamiento Nómade. (Recuperado de: http://clasesdeleuze.blogspot.com.ar/2009/04/clase-de-deleuze-I983.html)

(2005). Lógica del sentido.

Buenos Aires, Argentina, Editorial Paidós.

Derrida, J. (I968). Ousia et gramme. Santiago de Chile, Chile, Editorial Universitaria.

$$
\text { (1984). La tarjeta postal. }
$$

México DF, México, Siglo XXI Editores.

(I989). "Freud y la escena de la escritura" en La escritura y la diferencia. Barcelona. Editorial Anthropos.

(I995). Dar (el) tiempo. Buenos Aires: Editorial Paidós.

Dolar. M. (2006). Una voz y nada más. Buenos Aires, Argentina, Ediciones Manantial.

Freud, S. (I 894). "Sobre la justificación de separar de la neurastenia un determi- nado síndrome en calidad de "neurosis de angustia»" en Obras completas (Vol. 3) Buenos Aires, Argentina, Amorrortu.

(I 895). "Manuscrito E” en Obras completas (Vol. 1) Buenos Aires, Argentina, Amorrortu.

(I9I5 a). "Lo inconsciente" en Obras completas (Vol. 14) Buenos Aires, Argentina, Amorrortu.

(I9I 5 b). "La represión” en Obras completas (Vol. 14) Buenos Aires, Argentina, Amorrortu.

(I9I9). "Lo ominoso" en Obras completas (Vol. 17) Buenos Aires, Argentina, Amorrortu.

(I920). "Más allá del principio del placer" en Obras completas (Vol. 18) Buenos Aires, Argentina, Amorrortu.

(I926). "Inhibición, síntoma y angustia" en Obras completas (Vol. 20) Buenos Aires, Argentina, Amorrortu.

(I933). "Nuevas conferencias de introducción al psicoanálisis" en Obras completas (Vol. 20) Buenos Aires, Argentina, Amorrortu.

(I925). "La negación” en Obras completas (Vol. 19) Buenos Aires, Argentina, Amorrortu.

(I927). "El porvenir de una ilusión” en Obras completas (Vol. 21) Buenos Aires, Argentina, Amorrortu.

(I930). "El malestar en la cultura" en Obras completas (Vol. 21) Buenos Aires, Argentina, Amorrortu.

Glasman, S. (I993). La satisfacción. Conjetural. Buenos Aires, Argentina, Editorial Sitio.

KierkegaArd, S. (I984). El concepto de la angustia. Buenos Aires, Argentina, Hyspamerica. 